\title{
The Ahmed Versus Baerveldt (AVB) Study
}

\author{
Panos G Christakis and Iqbal I K Ahmed \\ Department of Ophthalmology and Vision Sciences, University of Toronto Faculty of Medicine, Toronto, Canada
}

DOI: https://doi.org/10.17925/USOR.2017.10.01.21

\begin{abstract}
$\mathrm{G}$ laucoma drainage devices are being increasingly used in the treatment of advanced glaucoma refractory to medical therapy or in cases that have failed trabeculectomy with antimetabolite. The Ahmed Versus Baerveldt (AVB) Study is an international, multicenter, randomized clinical trial comparing the two most frequently used devices. Five-year results have been recently published providing high quality evidence to guide a surgeon's decision on which device to use.
\end{abstract}

\section{Keywords}

Glaucoma drainage devices, aqueous shunts, Ahmed valve, Baerveldt tube, surgery

Disclosure: Iqbal I K Ahmed has received personal fees from Abbott Medical Optics and New World Medical. Panos $\mathrm{G}$ Christakis has nothing to disclose in relation to this article. No funding was received in the publication of this article. The Ahmed Versus Baerveldt study was funded by a research grant from the Glaucoma Research Society of Canada and a departmental challenge grant from Research to Prevent Blindness. This article is a short opinion piece and has not been submitted to external peer reviewers but was reviewed by the editorial board for accuracy before publication.

Authorship: All named authors meet the International Committee of Medical Journal Editors (ICMJE) criteria for authorship of this manuscript, take responsibility for the integrity of the work as a whole, and have given final approval to the version to be published.

open Access: This article is published under the Creative Commons Attribution Noncommercial License, which permits any noncommercial use, distribution, adaptation, and reproduction provided the original author(s) and source are given appropriate credit.

Received: January 11, 2017

Published online: February 17, 2017

Citation: US Ophthalmic Review, 2017;10(1):21-2

Corresponding Author: Iqbal K Ahmed, Department of Ophthalmology and Vision Sciences, University of Toronto Faculty of Medicine, 340 College Street, Suite 400,

Toronto, ON M5T 3A9, Canada. E: ike.ahmed@utoronto.ca
The treatment of glaucoma usually begins with the use of topical antiglaucoma medications or laser trabeculoplasty, with surgery reserved for cases refractory to, or at high-risk of failing medical management. ${ }^{1}$ Trabeculectomy with antimetabolite has traditionally been considered the preferred first-line filtration procedure. ${ }^{1}$ However, failure rates of approximately $50 \%$ at 5 years have been reported, as well as complications including hypotony, wound leak, and infection. ${ }^{2,3}$ Furthermore, 5-year results of the Tube Versus Trabeculectomy (TVT) Study found Baerveldt implantation had a higher success rate and lower rate of reoperation that trabeculectomy, with a similar intraocular pressure (IOP) reduction and need for glaucoma medications. ${ }^{3}$ As a result, there has been a significant change in practice patterns over the past two decades, with declining rates of trabeculectomy and an increase in the use of glaucoma drainage devices. ${ }^{4}$ In particular, glaucoma drainage devices are being increasingly used in patients who have failed trabeculectomy, or who have disease at high risk of failing trabeculectomy (e.g. neovascular or uveitic glaucoma). ${ }^{5}$

The two most frequently used glaucoma drainage devices are the Ahmed valve implant (New World Medical Inc, Rancho Cucamongo, CA, US) and the Baerveldt implant (Abbott Medical Optics, Santa Ana, CA, US). These devices differ in that the Ahmed implant has a venturi-based valve system which opens at $8-10 \mathrm{mmHg}$ and serves to prevent hypotony and its related complications. The Baervedlt implant lacks a built-in form of flow restriction and requires the surgeon to ligate the tube intraoperatively until adequate scar tissue has formed around the end-plate to regulate flow. Data comparing these devices is limited by its retrospective nature, differing patient populations and outcome criteria. As a result, selecting which glaucoma drainage device to use has largely been driven by surgeon experience and clinical site preference. ${ }^{6-9}$

The Ahmed Versus Baerveldt (AVB) Study is an international, multicenter, randomized clinical trial comparing these devices. ${ }^{10-13} \mathrm{~A}$ total of 238 patients were enrolled from six clinical centers and randomized to receive either an Ahmed-FP7 valve implant or a Baerveldt-350 implant. Patients had uncontrolled glaucoma despite maximum tolerated medical therapy, with a mean preoperative IOP of $31 \mathrm{mmHg}$ on three glaucoma medications. Trabeculectomy had failed in 37\% of patients, and many patients had disease at high risk of failing trabeculectomy including $21 \%$ with neovascular glaucoma and $10 \%$ with uveitic glaucoma. Due to the advanced disease of the study group, a strict IOP target of 5-18 mmHg was used based on data suggesting IOP >18 mmHg may result in progression. ${ }^{14}$

Both devices were effective in lowering IOP and the need for glaucoma medications. At 5 years, the mean IOP was $16.6 \mathrm{mmHg}$ in the Ahmed group (47\% reduction) and $13.6 \mathrm{mmHg}$ in the Baerveldt group ( $57 \%$ reduction, $p=0.001$ ). Mean medication use was 1.8 in the Ahmed group ( $44 \%$ reduction) and 1.2 in the Baerveldt group (61\% reduction, $p=0.03$ ). De novo glaucoma surgery was required in $18 \%$ of the Ahmed group and $11 \%$ of the Baerveldt group $(p=0.22)$. The 5 -year cumulative failure rate was $53 \%$ in the Ahmed group and $40 \%$ in the Baerveldt group ( $p=0.04$ ). Hypotony resulted in failure in five patients 
(4\%) in the Baerveldt group compared to none in the Ahmed group. Visual outcomes were similar in both groups $(p=0.88)$, with a modest decrease in vision from a median of 20/100 at baseline to 20/200 at 5 years.

The AVB Study results reinforce that both the Ahmed valve implant and the Baerveldt implant are effective treatments for refractory and high-risk glaucoma. The Baerveldt group had a lower failure rate and a lower IOP on fewer glaucoma medications than the Ahmed group, but carried a risk for hypotony. These results are similar to those of the Ahmed Baerveldt Comparison ( $\mathrm{ABC}$ ) Study, a concurrent multicenter randomized trial. ${ }^{15}$ The ABC Study found similar rates of failure between groups at 5-years (45\% Ahmed, 39\% Baerveldt, $\mathrm{p}=0.65$ ) but found the Baerveldt group achieved a lower IOP (Ahmed: $14.7 \mathrm{mmHg}$, Baerveldt: $12.7 \mathrm{mmHg}, \mathrm{p}=0.02$ ) on a similar number of medications (Ahmed: 2.2, Baerveldt: 1.8, $p=0.28$ ). However, the
Baerveldt group had a greater number of failures due to safety issues including persistent hypotony, explantation of the implant or loss of light perception (Ahmed: $8 \%$, Baerveldt: 17\%, $\mathrm{p}=0.03$ ).

The results of the AVB and $A B C$ Studies may be used by surgeons to individualize care for patients. If a patient requires an immediate postoperative IOP reduction and has a moderate long-term IOP target or has risk factors for postoperative hypotony_an Ahmed implant may be a good choice. If a patient has a low long-term IOP target or is intolerant or non-compliant with glaucoma medications-a Baerveldt implant may be a good choice. Ultimately, selecting a device should balance patient factors including goals of treatment and compliance with medical therapy with surgeon factors including their experience with each device and postoperative results. $\square$
1. Prum BE Jr., Rosenberg LF, Gedde SJ, et al., Primary OpenAngle Glaucoma Preferred Practice Pattern((R)) Guidelines, Ophthalmology, 2016;123:P41-P111.

2. Five-year follow-up of the Fluorouracil Filtering Surgery Study The Fluorouracil Filtering Surgery Study Group, Am J Ophthalmol, 1996;121:349-66.

3. Gedde SJ, Schiffman JC, Feuer WJ, et al., Treatment outcomes in the Tube Versus Trabeculectomy (TVT) study after five years of follow-up, Am J Ophthalmol, 2012;153:789-803 e2.

4. Desai MA, Gedde SJ, Feuer WJ, et al., Practice preferences for glaucoma surgery: a survey of the American Glaucoma Society in 2008, Ophthalmic Surg Lasers Imaging, 2011;42:202-8.

5. Minckler DS, Francis BA, Hodapp EA, et al., Aqueous shunts in glaucoma: a report by the American Academy of Ophthalmology, Ophthalmology, 2008:115:1089-98.

6. Wang $\mathrm{JC}$, See JL, Chew PT, Experience with the use of Baerveldt and Ahmed glaucoma drainage implants in an Asian population, Ophthalmology, 2004;111:1383-8.

7. Syed HM, Law SK, Nam SH, et al., Baerveldt-350 implant versus Ahmed valve for refractory glaucoma: a case-controlled comparison, J Glaucoma, 2004:13:38-45.

8. Goulet RI, 3rd, Phan AD, Cantor LB, WuDunn D, Efficacy of the Ahmed S2 glaucoma valve compared with the Baerveldt 250-mm2 glaucoma implant, Ophthalmology 2008;115:1141-7

9. Tsai JC, Johnson CC, Kammer JA, Dietrich MS, The Ahmed shunt versus the Baerveldt shunt for refractory glaucoma II: longer-term outcomes from a single surgeon, Ophthalmology 2006;113:913-7.

10. Christakis PG, Kalenak JW, Tsai JC, et al.. The Ahmed Versus Baerveldt Study: Five-Year Treatment Outcomes, Ophthalmology, 2016;123:2093-102
11. Christakis PG, Tsai JC, Kalenak JW, et al., The Ahmed versus Baerveldt study: three-year treatment outcomes, Ophthalmology 2013; 120:2232-40

12. Christakis PG, Tsai JC, Zurakowski D, et al., The Ahmed Versus Baerveldt study: design, baseline patient characteristics, and intraoperative complications, Ophthalmology 2011:118:2172-9.

13. Christakis PG, Kalenak JW, Zurakowski D, et al., The Ahmed Versus Baerveldt study: one-year treatment outcomes, Ophthalmology, 2011;118:2180-9.

14. The Advanced Glaucoma Intervention Study (AGIS): 7, The relationship between control of intraocular pressure and visual field deterioration. The AGIS Investigators, Am J Ophthalmol, 2000;130:429-40.

15. Budenz DL, Barton K, Gedde SJ, et al., Five-year treatment outcomes in the Ahmed Baerveldt comparison study, Ophthalmology, 2015;122:308-16. 